\title{
Food Habits of School Pupils in Tromsø, Norway, in the Transition from 13 to 15 Years of Age
}

\begin{abstract}
The aim of this study was to investigate the development of food habits in adolescents in Troms $\varnothing$, whether pupil behaviour regarding food habits had changed in grade 10 compared to grade eight, and whether this was linked to pupils` Home Economics lessons in grade nine.

A total of 606 adolescents ( 321 boys and 285 girls) were studied on two different occasions - 2002 and 2005, A food-frequency questionnaire comprising 16 different food and beverage groups was used. The questionnaire also enquired about food habits, the amounts consumed of some food items and the socioeconomic conditions of the participants and their families.

The frequency of eating breakfast, lunch and dinner reduced from 8th to 10th grade. No significant differences were found between 8th and 10th graders in their frequency of consuming fruit and vegetables. Tenth graders ate chocolate and snacks more often than 8th graders. Girls reported eating fruit and vegetables more often than boys. This applies to both 8 th and 10th graders. Far more pupils from both groups need to eat more fruit and vegetables every day.

The conclusion of the study is that food habits change significantly from the 8th to the 10th grade. Further progress must be achieved in addressing the issue of translating the theory of nutritional education into practice. More studies and evidence are required to understand the potential of the Home Economics curricula to change the unhealthy eating trends seen in this and other studies.
\end{abstract}




\section{Introduction}

This article presents the results of a part of a larger study of 8th and 10th grade boys and girls. Grade eight pupils are aged 13, while grade 10 pupils are 15 years old. The aim of the study was to describe, analyse and discuss the differences in food preferences and dietary habits of 8th to 10th graders based on a questionnaire comprising 48 questions, including questions about the pupils' social background.

The main question posed in this study is whether pupil behaviour regarding food habits had changed in grade 10 compared to grade eight, and whether this was linked to pupils' home economics lessons in grade nine.

This study is one of the few based on a substantial number of grown-up pupils living in a geographical area and climate that has previously been examined only on a small scale. It is one of very few of its kind carried out north of the Arctic Circle. The climate of the coastal areas of Northern Norway is greatly influenced by the North Atlantic Drift and is characterised by mild winters and cold summers - a typical Norwegian west-coast climate. Traditionally, the inhabitants of the west coast of Norway have made a living from small farms and fisheries. Fish and potatoes have been key ingredients in their food habits (Moe, 1997). Today, there is often the influence of international food items such as spaghetti, pizza and tacos. Still, traditional Norwegian food such as porridge, salted fish and meat constitutes a key part of the diet of people living in Northern Norway. The city of Troms $\emptyset$, also called the Gateway to the Arctic, is situated at almost $70^{\circ}$ North, and has traditionally been considered the capital of Northern Norway due to sealing, whaling and fishing in the Arctic Ocean from the 18th century onwards. In the Troms $\varnothing$ area, farmers have traditionally grown potatoes, Swedish turnips, cabbage, carrots and other vegetables (Moe, 1997). 
During late adolescence, changes in lifestyle are common. Adolescents are often easily influenced by trends and changes in the society. The mass media and advertisements in the press, on the radio and television are powerful factors behind changes in food habits. Today's adolescents grow up with more advertisements and commercials around them in the mass media, particularly television, than any other generation: this has a great impact on their food habits and physical activity (Fogelholm, 1998). Peer groups also greatly influence the individual food habits of adolescents, i.e. what kinds of food they liketo eat, their daily meal pattern and the composition of the meal.

The great majority of pupils can effectively be reached through schools, which is an appropriate arena for health promotion. The Norwegian educational system is administered both nationally and regionally. Primary school is compulsory from age six to 16 and comprises grades one to 10 , divided into primary (1-7) and lower-secondary (810) school. Home Economics is taught as a separate school subject in the ninth grade, three hours per week, whereas 8th grade pupils are not taught Home Economics. According to the National Curriculum, ninth grade pupils in Norway should be taught nutrition and meal patterns. In Home Economics, teachers should stress the importance of eating fruit and vegetables daily (The Norwegian Ministry of Education, 1996). School lunches are not usually available at Norwegian schools. Norwegian school pupils have to bring their lunches from home, in lunch boxes. In Troms $\varnothing$, adolescents can buy milk at school, but not fruit or vegetables (Øvrebø, 2000).

\section{Aim}

The aim of this article is to investigate the development of food habits in adolescents in Troms $\emptyset$ from the 8th to the 10th grade, and to explore whether some general trends in the 
food habits of these adolescents may be influenced by Home Economics teaching.

The specific aims were:

- chart the consumption of various foods and beverages by 13 and 15 -year-olds in Troms $\varnothing$, Norway

- chart the consumption of fruit and vegetables by 13 and 15-year-olds in Troms $\varnothing$, Norway

- investigate the gender differences between these age groups as regards the consumption of fruit and vegetables

- examine whether Home Economics teaching appears to influence food choices

\section{Methods}

\section{Sample and administration}

The study was conducted during the autumn of 2002 and the spring of 2005 using a questionnaire surveying all five lower-secondary schools in Troms $\varnothing$. All 8th graders at these schools were invited to take part in the baseline survey, 606 pupils in all. In 2005, 298 boys and 285 girls in the 10th grade completed the questionnaire. In the 2005 sample, the same pupils were asked as in the 2002 sample. These pupils were chosen because Home Economics is taught as a separate school subject in the ninth grade, whereas 8th grade pupils are not taught Home Economics. The subject has been structured into main subject areas for which competence aims have been formulated. These main subjects are: Food and lifestyle, food and culture and food and consumption. The main subject area Food and lifestyle focuses on developing skills and the motivation to choose a health-promoting lifestyle. Composing nutritionally safe and sound food, in accordance with guidelines for healthy eating from the health authorities, is an important basis for the teaching in this main subject area. Reflection upon the relationship between 
food, lifestyle and health is important. The aims for the education are that the pupil shall be able to plan and prepare safe and nutritionally good food, and explain the nutrient substances in the food.

The main subject area Food and consumption focuses on becoming accustomed with different food, labelling and production, and being a critical and responsible consumer. The aim for the education is that the pupil shall be able to assess and choose foodstuffs based on ethical and sustainable criteria.

Consequently, one would expect 10th graders to be more knowledgeable about nutrition than 8th graders and that this increased knowledge would influence their choices of food items.

The head teachers at these schools were asked for permission for their pupils to participate in the study. All parents were contacted through the pupils and were asked for their written permission for their children to participate. In this way, the legal and formal aspects of the study were attended to, and anonymity was guaranteed for the pupils who participated. The teachers gave a questionnaire to all pupils present in class on the day of the survey. The questionnaire was filled in by the pupils themselves in class after the teacher had given brief instructions. They were asked to think about their usual habits when filling in the food-frequency section.

Methodologically, this paper is largely based on quantitative analysis. The quantitative analysis is a statistical analysis based on all the answers from 606 questionnaires in 2002 and 583 questionnaires in 2005.

The questions dealt with in this article are those that were possible to answer precisely by the pupils involved, thereby providing information of a nature that could be treated statistically. 
In the spring of 2005, the pupils who had answered the questions in 2002 were asked the same questions as before. The questionnaire used in 2005 had additional questions, including some about the subject of Home Economics. In the present longitudinal investigation there were 298 boys and 285 girls. By 10th grade, 23 of the pupils from 8th grade had left the study.

\section{Food frequency questionnaire}

The food frequency questionnaire developed was guided by the international literature available, focus-group interviews with Norwegian 8th and 10th graders (Øvrebø, 2000) and by the theoretical framework provided by Social Cognitive Theory (Bandura, 1986). SCT postulates that behaviour, including dietary behaviour, is the result of environmental factors (such as easily accessible fruit and vegetables or by observing important others performing the behaviour) and personal factors (such as preferences or self-efficacy). However, the development of the theoretical framework of the questionnaire was mainly inspired by Flay`s Theory of Triadic influences (Flay \& Petriatis, 1994) and extended with constructs from the `attitude, social influences, self-efficacy (ASE) model (de Vires et al., 1988; Kok et al., 1996) and Bandura`s Social Cognitive Theory (Bandura, 1997). The food frequency questionnaire was a self-administered, food-frequency questionnaire (FFQ). The Self-Efficacy model (ASE) belongs to the cognitive theory that mental processes (reasoning and planning) precede the performance of the behaviour (Lien, 2001). Furthermore, this value expectancy theory, which means that the subjective value of an outcome and the subjective expectancy of that the behaviour, will lead to that outcome causes the subject to perform (or not perform) a specific behaviour (Lien, 2001). A food-frequency questionnaire (FFQ) can be used to assess the usual diets of individuals 
and to rank people according to their intake of fruit and vegetables (Nelson \& Bingham, 1997). The FFQ is a reliable questionnaire that can be used to rank subjects for most food items, although one must consider overestimation whenever the FFQ is used to estimate prevalence (Vereecken \& Maes, 2003). Several studies have used self-completed foodfrequency questionnaires (Thompson et al., 1999; Inchley et al., 2001; Lien et al., 2001; Haapalathi et al., 2003; Robinson et al., 2004; Sandvik et al., 2005), whereas other studies have used 24-hour recall as methods (Reynolds et al., 1999; Øverby et al., 2002). Compared to the validation method applied in this study, the 24-hour recall employed in a study by Andersen and colleagues overestimated the intake of fruit (Andersen et al., 2004). However, the 24-hour recall method has been demonstrated to produce consistent responses over a 14-day test/retest study period (Andersen et al., 2004). When applied to the differences between groups, however, this potential overestimation is not regarded as a major concern and does not represent a threat to the validity of the findings reported.

Several studies have evaluated the validity of FFQs for use with older children and adolescents, yielding inconsistent results. Another study demonstrated close correspondence between the FFQ and the 24-hour recall for most items. Only cereals, diet soft drinks and other milk products recorded considerably higher food frequencies than expected from 24-hour recall (Vereecken et al., 2003). Results from that study indicate that the FFQ demonstrates sufficient reliability and validity to be useful in ranking subjects according to their consumption of the individual food itemsincluded. The FFQ included 16 items assessing the habitual intake of various types of food. A pilot project was conducted the same year. Consequently, the final wordings of the questionnaire were modified according to responses from the pupils and teachers. The previous day's intake was recorded for school days, i.e. the survey was conducted on 
weekdays, Tuesday through to Friday. To help the pupils recall their consumption, the day was divided into five periods, asking about each period separately. The five periods were in accordance with the usual Norwegian meal pattern of breakfast (before school), lunch (at school), after-school meal, dinner and supper (after dinner). To help the adolescents remember, a question concerning whether they had eaten a meal (breakfast, lunch, dinner or supper) the previous day was introduced in every time block except for the no-meal period "after school". The pupils recorded what kinds and the amounts of fruit and vegetables they ate at different times in household measures (e.g. one apple, 12 grapes). Also, to avoid any misunderstanding, a separate question concerning potato consumption was added. Juice and potatoes were not included in the fruit and vegetable calculations.

Habitual intake of fruit and vegetables was measured by a sum score of four frequency questions:

- How often do you eat vegetables for dinner?

- How often do you eat vegetables in addition to dinner? (e.g. a carrot for school lunch)

- How often do you eat apples, oranges, pears or bananas?

- How often do you eat other types of fruit and berries?

A sum score was made based on the following items: "How often do you drink fizzy drinks (containing sugar) water, juice, squash and milk?"; "How often do you eat brown bread, fish for dinner, pizza, hamburgers/hot dogs, cod-liver oil, French fries, snacks, sweets (e.g. chocolates, mixed sweets) and crisps?" One of the following options should be chosen as an answer: every day, several times a day, 4-6 times per week, 1-3 times per week, once or twice a month, or never. For "How often do you eat lunch at school?", one 
of the following should be chosen: 5 times per week, 3-4 times per week, 1-2 times per week, seldom, never. This resulted in a very low frequency of unanswered questions.

\section{Data collection and analysis}

The teachers gave the questionnaire to all pupils present in class on the day of the survey. The questionnaire was filled in by the pupils in class after the teacher had given brief instructions. Each questionnaire was accompanied by a letter explaining the main expressions used and how to answer the questionnaire. The participants were asked to think about their usual habits when filling in the food-frequency section.

To ensure high participation rates by schools and good compliance by adolescents, it was important that most of the adolescents were able to finish the questionnaire within one school session (45 minutes).

One limitation was that the pupils were asked only about their consumption frequency and no data were gathered to determine the portion size. However, in general, portion sizes are difficult to estimate accurately, particularly in countries where people are not used to the concept of portion size. In addition, it is not clear from the literature whether additional questions about portion sizes in food-frequency questionnaires add substantially to the assessment of dietary intake, as some authors have found no improvement in relative validity (Margetts et al., 1989; Tjonneland et al., 1992), while others have reported an improvement (Block et al., 1990; Jackson et al., 1990; Kuskowska-Wolk et al., 1992).

The data collected were systemised and entered into the Excel programme. For 
presentation and statistical treatment, the SYSTAT programme was used (Wilkinson, 2000). All statistical handling was based on $\chi^{2}$ tests following the guidelines in wellknown statistical literature. Chi-squared tests were used to compare differences between age groups, genders and food/drink consumption frequencies (King \& Minium, 2008). Data were presented for the two different age groups and were divided by gender. The frequencies of responses given by girls and boys with $95 \%$ confidence intervals were computed for all variables.

\section{Results}

Table 1

Table 1 shows how often the pupils ate breakfast, school lunch, dinner, supper and snack between meals.

\section{Breakfast.}

There were significant differences in breakfast habits between 8th and 10th graders. More than $86.6 \%$ of the adolescents in 8 th grade ate breakfast every day, while $81.3 \%$ of the 10th graders ate breakfast twice a week or less.

\section{School lunches.}

The pupils ate school lunch more often int 8th grade than in 10th grade.

Only $39.5 \%$ of the adolescents in 10th grade have school lunch five days a week. The adolescents have lunch more often in 8th grade with $59.1 \%$ eating lunch five days a week.

\section{Dinner.}

The pupils ate dinner more often in 8th grade than 10th grade. Most pupils ate dinner every day. In the 8 th grade, $93.4 \%$ have dinner every day. Of the 10 thgrade, $86.9 \%$ of pupils have dinner daily. Significant differences were found between the 8th and 10th 
graders in their consumption of dinner.

\section{Supper.}

The number of pupils who ate supper changed between the 8th grade and 10th grade.

The frequency of eating breakfast, school lunch and dinner was reduced from the 8th grade to the 10th grade.

\section{Snack between meals:}

Many adolescents ate snacks between meals daily (41.5\% in 10th grade and $38.3 \%$ in 8 th grade). No significant differences were found between the 8th and 10th graders in their consumption of snacks between meals.

Table 2 shows that 10th graders ate chocolate and snacks more often than 8th graders $(\mathrm{P}<0.001)$. "Often" was defined as every day, a number of times a day, and 4-6 times a day. As for gender differences, 10th -grade boys had a significantly higher intake of snacks $(\mathrm{P}<0.01)$, chocolate $(\mathrm{P}<0.001)$, hamburgers $(\mathrm{p}<0.001)$, pizza $(\mathrm{p}<0.001)$ and chips $(\mathrm{P}<0.05)$ than 10 th grade girls and 8th graders. 8th grade boys had a significantly higher intake of hamburgers than 8th grade girls. 10th grade boys had a significantly higher intake of pizza than both 8th grade girls and boys and 10th grade girls. No significant differences were found between the 8th and 10th graders in their consumption of brown bread, fish and cod-liver oil.

Table 3 shows that the daily consumption pattern of water, juice, squash, fizzy drinks and milk did not change for girls. But more 10th grade boys drank fizzy drinks and juice than 8th graders.

Figure 1 shows that of the 8th graders, $19.6 \%$ of the boys and $24.3 \%$ of the girls ate 
vegetables every day and/or several times a day. $21.5 \%$ of the 10th-grade boys and $31.3 \%$ of the girls ate vegetables every day and/or several times a day. No significant differences were found between the 8th and 10th graders in their frequency of vegetable consumption, but more girls than boys ate vegetables daily and 4-6 times per week. This applied to both the 8th and 10th graders $(\mathrm{P}<0.01)$. There is a slight increase from the 8th to the 10th grade in the consumption of vegetables daily and/or several times a day. This applies to the girls. However, this increase is not significant.

Table 4 shows that over one-quarter of the adolescents consumed 0-3 vegetables weekly and this is applicable to both the 8th and 10th graders. Scarcely $20 \%$ in the 8 th grade and scarcely $25 \%$ in the 10 th grade consume 12 or more vegetables weekly. This applies to both girls and boys.

There was no significant difference in the daily consumption of fruit from the 8 th to the 10th grade (Figure 2). Of the 8th graders, $28.3 \%$ of the boys and approximately $37.5 \%$ of the girls ate fruit and berries daily. Of pupils who were two years older, however, $30.5 \%$ of the 10th grade boys consumed fruit and berries daily, and $44.2 \%$ of the 10 th grade girls consumed fruit and berries daily or several times a day. Fewer boys than girls in both the 8th and 10th grades consumed fruit and berries daily $(\mathrm{P}<0.01)$. There was a slight increase in daily fruit consumption, but it is not significant.

Approximately $28 \%$ of the 8 th graders consumed 10 or more pieces of fruit weekly. Of the 10 th graders, scarcely $20 \%$ consumed 10 or more pieces of fruit weekly (Table 1). Of the 8th graders, only $17.7 \%$ of the boys and $16.8 \%$ of the girls consumed 13 or more pieces of fruit weekly. Of the 10th graders, only $15.1 \%$ of the boys and $15.4 \%$ of the girls consumed 13 or 
more pieces of fruit weekly. But $28.9 \%$ of the 10 th graders consumed seven to nine pieces of fruit weekly. Fewer 10th graders than 8th graders eat 10 or more pieces of fruit per week.

\section{Discussion}

The same standardised FFQ, with unchanged measurement procedures, was used on both study occasions. Using an FFQ does not produce quantitative data on the intake of energy or nutrients. On the other hand, repeated assessments in a population using this method facilitate detecting changes in the dietary intake pattern. The strength of the present study is its longitudinal approach, which provides an opportunity to follow the same adolescents on two different occasions.

Dinner is the only hot meal in a typical Norwegian diet; breakfast, lunch and supper are bread-based meals. It is usual for Norwegian children to have both dinner and supper. Many pupils have dinner every day. Although the Norwegian dinner pattern has been characterized by an increasing multicultural complexity in recent decades, conventional Norwegian dishes still predominate (Bugge \& Døving, 2000;Bugge, 2005).

The frequency of eating breakfast, lunch and dinner reduced from 8th to 10th grade.

This concurs with previous studies in the Nordic countries showing that younger children have more regular meal patterns than adolescents (Hagman et al., 1986, Frost Andersen et al., 1997). Other recent studies have also shown that adolescents who skip breakfast or lunch tend to have a poorer diet than those who habitually eat these meals (Haapalathi et al., 2003). According to the competence under the main subject Food and lifestyle in Home Economics, teachers should stress the importance of eating breakfast, lunch and dinner daily. 
From the 8th to 10th grade, there was no increase in the consumption of brown bread, fish for dinner or cod-liver oil. But there was an increase in fast food, hamburgers, hot dogs and pizzas. Tenth grade boys eat significantly more chocolate, snacks and chips more often than 8th graders and 10th grade girls. No significant differences were found between grades or gender as concerns the consumption of water, squash and milk. The daily consumption of sugary fizzy beverages changed from the 8th to the 10th grade. Several more 10th graders drank fizzy drinks daily compared to the intake of 8th graders. Of the pupils, more 10th grade boys $(74 \%)$ drank fizzy drinks daily $(\mathrm{P}<0.001)$ than 10 th grade girls and 8th graders. There were also significantly more 10th grade boys who drank juice daily than 10th grade girls and 8th graders. The adolescents' dietary habits change adversely from the 8 th to the 10th grade, and the 10th grade boys in particular have developed poorer drinking and eating patterns. Other studies have shown that the consumption of soft drinks increases with age (Klepp et al., 1996; World Health Organisation, 2000; Lytle et al., 2000), especially amongst boys (King et al., 1996, von Post-Skagegård et al., 2002).

Advertising may have a stronger influence on the 10 graders than 8th graders. Much of the advertising directed towards young people, or that is broadcast in association with programmes that are interesting for young people, is advertising for different types of foods that have a high sugar, fat - and / or salt content. In Home Economics under the main subject Food and consumption, young people are taught about how advertising can influence consumers' food choices. It may be that advertising has a greater impact on young people than the teaching of Home Economics.

The consumption frequency of fast food increased significantly in both sexes, especially among the males, who had the largest increase in the frequency of the consumption of fast food. In southern European countries, snacking seems to be less frequent, but it is difficult to 
compare results from local studies since they are often not representative of the countries (Amorim Cruz, 2000). In Sweden, Höglund et al. (1998) have shown that females tended to eat healthier food, i.e. vegetables, more often than males. The females, however, had a tendency for a more irregular meal pattern, whereby they often skipped breakfast and dinner, but they did not compensate for this by eating fast food, unlike the males.

There was no increase in the daily consumption of fruit and vegetables from the 8th to the 10th grade. The number of pieces of fruit has in fact decreased from the 8th to the 10th grade (see table 1).

This study shows that in both the 8th and 10th grades, the frequency of fruit consumption is higher than the corresponding frequency for vegetables. It is easier to increase the intake of fruit than that of vegetables for this age group. Fruit is basically "ready-to-eat" straight from the supermarket, whereas vegetables often require preparation before eating. However, it is important to promote both fruit and vegetables as both have beneficial effects in disease prevention. It is therefore important to find ways to increase the young people's intake of vegetables and fruit, and future programmes should attempt to achieve this.

To meet the national recommendation, all Norwegians should eat vegetables for dinner every day. Vegetables are typically eaten for dinner in Norway, and not having vegetables for dinner would make it difficult, if not impossible, to reach the recommended three-a-day. Other studies have shown that Norwegian adolescents' consumption of vegetables for dinner is too low (Vejrup et al., 2008). Norwegian adolescents consume fewer vegetables than recommended. There are now studies containing data on vegetables consumed for dinner by adolescents in the Nordic countries, but studies concerning the overall consumption of vegetables by adolescentsindicate an overall low intake (Samuelson, 2000). Other studies show that children seldom eating vegetables for dinner at age 12 also seldom tend to do so at age 15 (Vejrup et al., 2008). 
The study shows that the frequency of the intake of fruit and vegetables in the diets of the 8th and 10th graders in Troms $\varnothing$ was below the international mean (National Nutrition Council, 1996; Øverby et al., 2002). There is a traditional culture for eating little vegetables and fruit in Troms $\emptyset$, as the geographical location and climate influence the food habits. It's just a hot meal a day and little tradition of eating fruits and vegetables with bread-based meals. But in the teaching of Home Economics, according to competence under the main subject Food and culture, the pupils learn that food which is nutritionally poor should be changed.

Approximately one quarter of the adolescents consumed three or fewer vegetables per week than recommended, and three or fewer pieces of fruit per week. This applies to both the 8th and 10th graders. This concurs with national dietary surveys showing that Norwegians on average eat only about half the recommended "five-a-day", and that intake is especially low amongst adolescents (National Nutrition Council, 1996; Johansson \& Andersen, 1998; $\emptyset$ verby \& Andersen, 2002). This low consumption is of public health concern, particularly since health-related behaviour patterns developed at a young age are considered important determinants of such patterns later in life (Kelder et al., 1994; Lien et al., 2001, Hu \& Willet, 2002).

The questionnaire was completed in May 2005 by the 10th graders, just under a year after they had been taught Home Economics. According to the National Curriculum, 9th graders should learn about nutrition in Home Economics classes. The aims for the education are that the pupil shall be able to compare meals pupils prepare themselves with eating guidelines from the health authorities.

The results from this study tend to show that the teaching of Home Economics in the ninth 
grade might not have been successfulin terms of producing better food habits among pupils. This study is a longitudinal study. Therefore, the point about Home Economics could be justifiable. There could be several reasons why fewer 10th graders than 8 th graders do not eat fruit and vegetables often - perhaps the teaching method in Home Economics classes does not adequately stress the importance of eating fruit and vegetables. The study shows that the pupils thought the teaching in Home Economics was poor and that there had been no such focus on eating more fruit and vegetables. The results also show that over half the pupils were not more positive about eating fruit and vegetables because of Home Economics lessons (Øvrebø, 2008).

However, it may be the case that the subject of Home Economics does not apply fruit and vegetables in the menus used. Sometimes, the Home Economics teacher is not properly qualified; he or she lacks the necessary skills (Øvrebø, 2000). In such cases, the teaching will suffer. Earlier studies have shown that teaching the topic of nutrition does not take place during the lessons. The teachers teach the pupils cooking techniques and not nutrition or meal patterns. Little time is spent on nutrition-related subjects in the teaching of Home Economics in Norway(Øvrebø, 2003).

Other studies have shown that education has a limited role when an adolescent is making food choice (Walsh, A. \& Nelson, R., 2010). Walsh \& Nelson's study shows that knowledge of food was found to have no relation to their dietary behaviour and the achievement of a balanced diet. Therefore, further progress must be achieved in addressing the issue of translating the theory of nutritional education into practice.

Other studies (von Normann, 2009) have also shown that because food-related knowledge and home-keeping skills are no longer taught at home, school has to educate the children to make healthier food and lifestyle choices. 
The frequency of the intake of fruit and vegetables was higher for girls than for boys. Some girls, about $4.2 \%$, increased their consumption of fruit from the 8 th to the 10 th grade. There was also a slight increase $(6.9 \%)$ in the consumption of vegetables by girls from the 8 th to the 10th grade.

The fact that girls reported eating vegetables more frequently than boys has also been shown in previous research (Reynolds et al., 1999; Thompson et al., 1999; Inchley et al., 2001). The diet of girls tends to be better than that of boys as far as nutrition is concerned. Gender has also been found to be a predictor of an unhealthy diet in the adult population, with men more likely to consume fewer pieces of fruit and vegetables than women. Girls appeared to be more weight-conscious than boys in choosing vegetables more often (Haapalathi et al., 2003). Other studies have shown that teaching has a marked effect on food choices for girls of this age (Robinson et al., 2004). Perhaps the teaching method in Home Economics classes should pay heed to the different interests of girls and boys regarding fruit and vegetables. Therefore, there is a need for differentiated teaching according to gender, e.g. it would be important to stress teaching methods that emphasise the pupils' own activities. A form of teaching that focuses on fruit and vegetables and on the health effect of a higher intake of these could improve the pupils' attitudes, increase their knowledge and also increase their intake of fruit and vegetables.

\section{Conclusion}

Food habits change significantly from the 8th to 10th grade. Further progress must be achieved in addressing the issue of translating the theory of nutritional education into practice. As girls have a better food habits than boys, there is a need for differentiated teaching according to gender. Morestudies and evidence are required to understand the potential of the 
Home Economics curricula to change the unhealthy eating trends seen in this and other studies.

\section{Acknowledgements}

The author wishes to acknowledge the head teacher and classroom teacher from the schools involved with the project. 


\section{References}

Amorin Cruz, C.A. (2000) Dietary habits and nutritional status in adolescents over Europesouthern Europe. European Journal of Chinical Nutrion, 54, 29-35.

Bandura, A. (1986) Social Foundations of Thought and Action: A Social Cognitive Theory. Englewood Cliffs, NJ: Prentice Hall, UK.

Bandura, A. (1997) Self-efficacy and health behaviour. In: Cambridge handbook of psychology, health and medicine (ed. by. A. Baum, S. Newman, J. Wienman, R. West \& C. McManus), pp. 160-162. Cambridge: Cambridge University Press.

Berg, C., Jonsson, I., Conner, M. \& Lissner, L. (2003) Perception and reasons for choice of fat and fibre-containing food by Swedish schoolchildren. Appetite, 40, 61-67.

Block, G., Woods, M., Potosky, A. \& Clifford, C. (1990) Validation of a self-administered diet history questionnaire using multiple diet records. Journal of Clinical Epidemiology, 43,1327-1335.

Bugge, A. \& Døving, R. (2000) The Norwegian meal pattern. SIFO-report no 2. Oslo: National Institute for Consumer Research.

Bugge, A. (2005) Dinner - A sciological analysis of Norwegian dinner practice (doctoral dissertation). Trondheim: Norwegian University of Science and Technology (NTNU). 
De Vries, H., Dijkstra, M. \& Kuhlman, P. (1988) Self-efficacy: The third factor besides attitude and subjective norm as a predictor of behavioural intentions. Health Education Research, 3, 273-282.

Flay, B.R., \& Petraitis, J. (1994) The theory of triadic influence: A new theory of health behaviour with implications for preventive interventions. In Albrecht, G.S. (Ed.) Advances in Medical Sociology, Vol IV: A reconsideration of models of health behaviour change. Greenwich, CN: JAI Press.

Fogelholm, M. (1998) Diet, physical activity and health in Finnish adolescents in the 1990s. Scandinavian Journal of Nutrition, 42, 10-12.

Frost Andersen, L., Nes, M., Bjorneboe, G-EA. \& Drevon, CA. (1997) Food habits among 13-year-old Norwegian adolescents. Scandinavian Journal of Nutrition, 41, 150-154.

Hagman, U., Bruce, A., Persson, LA., Samuelson, G. \& Sjolin, S. (1986) Food habits and nutrient intake in childhood in relation to health and socio- economic conditions. A Swedish Multicentre Study 1980-91. Acta Paediatrica, 328, 1-56.

Hu, F.B. \& Willet, W.C. (2002) Optimal diets for prevention of coronary heart disease. Journal of the American Medical Association, 288, 2569-2578.

Høglund, D., Samuelson, G. \& Mark, A. (1998) Food habits in Swedish adolescents in relation to socioeconomic conditions. European Journal of Chinical Nutrion, 52, 784-789. 
Haapalathi, M., Mykkänen, H., Tikkanen, S. \& Kokkonen, J. (2003) Meal patterns and food use in 10- to 11-year-old Finnish children. Public Health Nutrition, 6, 365-370.

Inchley, J., Todd, J., Bruce, C. \& Currie, C. (2001) Dietary trends among Scottish schoolchildren. Journal of Human Nutrition and Dietetics, 14, 207-216.

Jackson, N., Little, J. \& Wilson, A.D. (1990) Comparison of diet history interview and selfcompleted questionnaire in assessment of diet in an elderly population. Journal of Epidiology and Community Health, 44, 162-169.

Johansson, L. \& Andersen, L.F. (1998) Who eats 5 a day? Intake of fruit and vegetables among Norwegians in relation to gender and lifestyle. Journal of the American Dietetic Association, 98, 689-691.

Kelder, S.H., Perry, C.L., Klepp, K.-L. \& Lytle, L.A. (1994) Longitudinal tracking of adolescent smoking, physical activity, and food choice behaviours. American Journal of Public Health, 84, 1121-1126.

King, A.J.C., Wold, B., Tudor-Smith, C. \& Harel, Y. (1996) The health of youth: Acrossnational survey. World Health Organization Regional Office for Europe, Copenhagen, Denmark.

King, B.M. \& Minium, E.W. (2008) Statistical reasoning in the behavioural sciences, $5^{\text {th }}$ ed. John Willey \& Sons, New York, USA. 
Klepp, K.-I., Halvorsen, M., Bjorneboe, G.E. \& Wold, B. (1996) Evaluating 'Food in the Schools' - Changes over time in reported meal frequency among Norwegian school children. Scandinavian Journal of Nutrition, 40, 113-116.

Kok, G., Schaalma, H., De Vries, H., Parcel, G. \& Paulussen, T. (1996) Social psychology and health education. European Review of Social psychology, 27, 471-482.

Kuskowska-Wolk, A., Holte, S., Ohlander, E.M., Bruce, A., Holmberg, L., Adami, H.O. \& Bergstrom, R. (1992) Effects of different designs and extension of a food frequency questionnaire on response rate, completeness of data and food frequency responses. International Journal of Epidemiology, 21, 1144-1150.

Lien, N. (2001) Stability and predictors of eating behaviours during adolescence and early adulthood (Ph.D. thesis). Institute for Nutrition Research, University of Oslo, Oslo.

Lien, N., Lytle, L.A. \& Klepp, K.-I. (2001) Stability in Consumption of Fruit, Vegetables, and Sugary Foods in a Cohort from Age 14 to age 21. Preventive Medicine, 33, 217-226.

Lytle, L.A., Seifert, S., Greenstein, J. \& McGovern, P. (2000) How do children's eating patterns and food choices change over time? Results from a cohort study. American Journal of Health Promotion, 14, 222-228.

Margetts, B.M., Cade, J.E. \& Osmond, C. (1989) Comparison of a food frequency questionnaire with a diet record. International Journal of Epidemiology and Community Health, 57, 218-225. 
Moe, N.H. (1997) Traditional Food from the North. Victus Publishing Company, Troms $\varnothing$, Norway.

National Nutrition Council (1996) Recommendations for Increased Intake of Fruit and Vegetables. National Nutrition Council, Oslo, Norway.

Reynolds, K.D., Baranowski, T., Bishop, D.B., Farris, R.P., Hyg, M.S., Binkley, D., Nicklas, T.A. \& Elmer, P.J. (1999)Patterns in Child and Adolescent Consumption of Fruit and Vegetables: Effects of Gender and Ethnicity across Four Sites. Journal of the American College of Nutrition, 18, 248-254.

Robinson, S.M., Crozier, S.R., Borland, S.E., Hammond, J., Barker, D.J.P. \& Inskip, H.M. (2004) Impact of educational attainment on the quality of young women's diet. European Journal of Clinical Nutrition, 58, 1174-1180.

Samuelson, G. (2000) Dietary habits and nutritional status in adolescents over Europe. An overview of current studies in the Nordic countries, European Journal of Clinical Nutrition, 54, 21-28.

Sandvik, C., De Bourdeaudhuij, I., Due, P., Brug, J., Wind, M., Bere, E., Perez-Rodrigo, C., Wolf, A., Elmadfa, I., Thorsdottir, I., Vaz de Almeida, M.D., Yngve, A. \& Klepp, K.-I. (2005) Personal, Social and Environmental Factors regarding Fruit and Vegetable Intake among Schoolchildren in Nine European Countries. Annual Nutrition and Metabolism, 49, 255-266. 
The Norwegian Ministry of Education (1996) The curriculum for the 10-year compulsory school. Norwegian Board of Education, Oslo, Norway.

Thompson, R.L., Margetts, B.M., Speller, V.M. \& McVey, D. (1999) The Health Education Authority's health and lifestyle survey 1993: who are the low fruit and vegetable consumers? Journal of Epidemiology \& Community Health, 53, 294-299.

Tjonneland, A., Haraldsdottir, J., Overvad, K., Stripp, C., Ewertz, M. \& Jensen, O.M. (1992) Influence of individually estimated portion size data on the validity of a semi-quantitative food frequency questionnaire. Journal of Epidemiology and Community Health, 21, 770-777.

Vejrup, K., Lien, N., Klepp, K.-I. \& Bere, E. (2008) Consumption of vegetables at dinner in a cohort of Norwegian adolescents. Appetite, 51, 90-96.

Vereecken, C. \& Maes, L. (2003) A Belgian study on the reliability and relative validity of the Health Behaviour in School-Aged Children food frequency questionnaire. Public Health Nutrition, 6, 581-588.

von Normann, K (2009) The impact of lifestyles and food knowledge on food patterns of German children. International Journal of Consumer Studies, 33, 282-391.

von Post-Skagegård, M., Samuelson, G., Karlström, B., Mohsen, R., Berglund, L. \& Bratteby, L.-E. (2002) Changes in food habits in healthy Swedish adolescents during the transition from adolescence to adulthood. European Journal of Chinical Nutrion, 56, 532-538. 
Walsh, A. \& Nelson, R. (2010) The link between diet and health: an exploratory study of adolescents in Northern Ireland using foodmaps. International Journal of Consumer Studies, 34, 190-195.

Wilkinson, L. (2000) SYSTAT for Windows: Statistics, Version 9.0 Edition. SYSTAT, Evanston, Illinois, USA.

World Health Organisation (2000) Health and health behaviour among young people. Geneva: WHO Regional Publications, Geneva, Switzerland.

Øverby, N.C. \& Andersen, L.F. (2002) Ungkost 2000. Nationwide dietary survey among $4^{\text {th }}$ and $8^{\text {th }}$ graders in Norway (in Norwegian with English abstract). Directorate for Health and Social Affairs, Department for Nutrition, Oslo, Norway.

Øvrebø, E.M. (2000) Dietary habits among 14-year-old schoolchildren in Murmansk and Troms $\varnothing$ (in Norwegian with English abstract). Troms $\varnothing$ University College, Faculty of Education, Troms $\varnothing$, Norway.

Øvrebø, E.M. (2003) Education in the subject Home Economics (in Norwegian with English abstract). Troms $\varnothing$ University College, Faculty of Education, Troms $\varnothing$, Norway.

Øvrebø, E.M. (2008) A comparative study of food habits amongst 13- and 15-year-old school children in Tromsø. Journal of the Home Economics Institute of Australia,15, 12-19. 


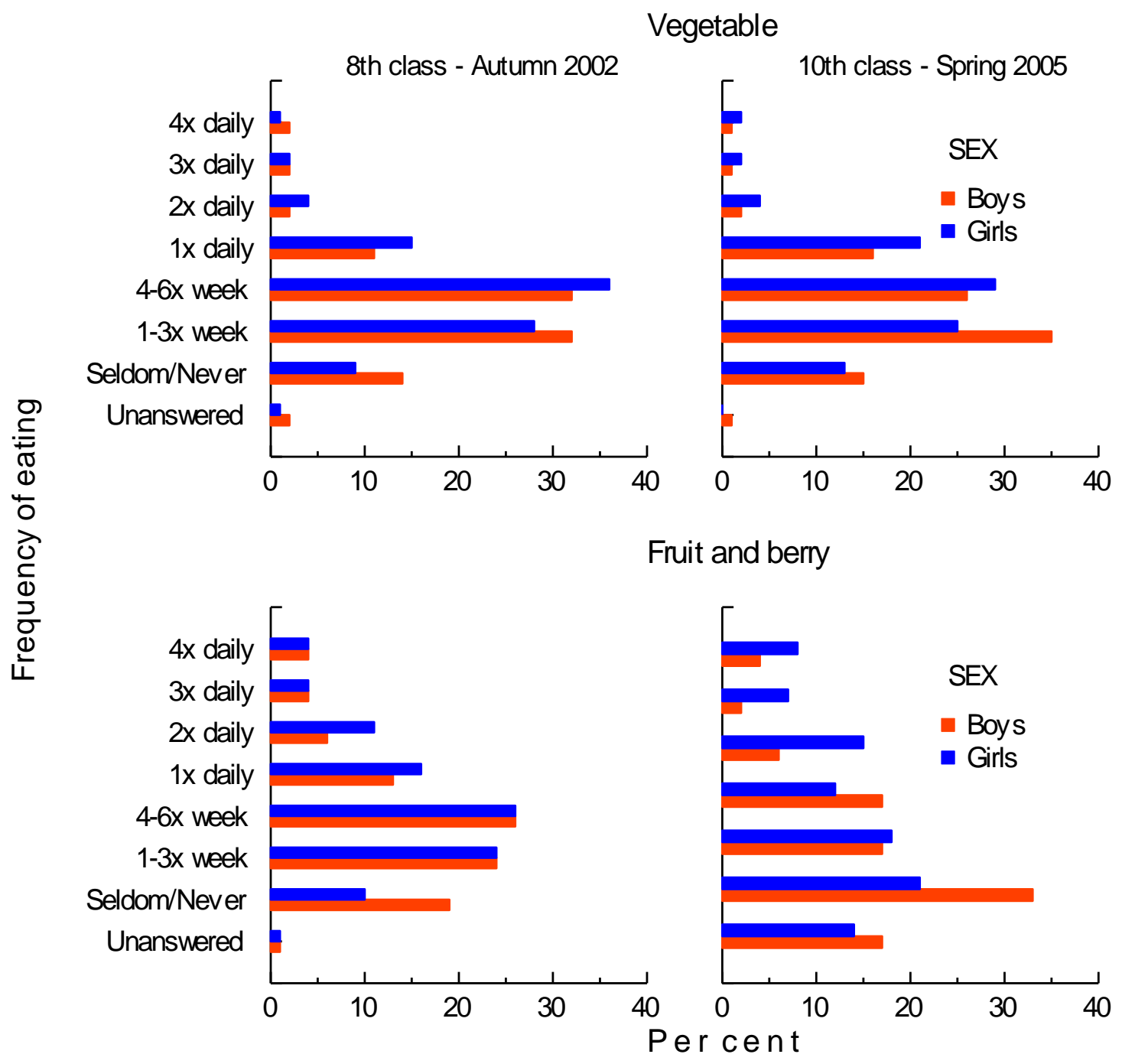

Figure 1 . Frequency of consumption of vegetables, fruit and berry amongst $8^{\text {th }}$ and $10^{\text {th }}$ graders in Troms $\varnothing$ 
TABLE 1

Change in meal pattern

\begin{tabular}{|l|l|l|l|}
\hline & eighth grade & tenth grade & Difference $\mathrm{p}$ \\
\hline Breakfast, daily & & & \\
\hline School lunch, 5 days a week & $\mathbf{8 6 . 6 \%}$ & $\mathbf{8 1 . 3 \%}$ & $*$ \\
\hline Dinner, daily & $\mathbf{9 3 . 4 \%}$ & $\mathbf{3 9 . 5 \%}$ & $* *$ \\
\hline Supper, daily & $\mathbf{8 0 . 0 \%}$ & $\mathbf{6 9 . 2 \%}$ & $*$ \\
\hline Snack between meal & $\mathbf{3 8 . 3 \%}$ & $\mathbf{4 1 . 5 \%}$ & NS \\
\hline
\end{tabular}

Asterisks denote the level of statistical significance revealed by logistic regression: $* \mathrm{P}<0.05$; $* * \mathrm{P}<0.01 ; * * * \mathrm{P}<0.001$. NS indicates that change in consumption is not significant. 
Table 2. Changes in food consumption by gender and grade.

\begin{tabular}{|c|c|c|c|c|c|}
\hline & \multicolumn{2}{|c|}{ eighth grade } & \multicolumn{2}{|c|}{ tenth grade } & \multirow[b]{2}{*}{ Difference p } \\
\hline & Girls & Boys & Girls & Boys & \\
\hline $\begin{array}{l}\text { Brown bread } \\
\text { Daily > } \\
4-6 \text { times per week } \\
1-3 \text { times per week }\end{array}$ & $\begin{array}{l}54.8 \\
14.7 \\
12.3 \\
\end{array}$ & $\begin{array}{l}59.6 \\
14.3 \\
15.9 \\
\end{array}$ & $\begin{array}{l}58.4 \\
15.4 \\
11.3 \\
\end{array}$ & $\begin{array}{l}59.4 \\
12.1 \\
12.5\end{array}$ & $\begin{array}{l}\text { NS } \\
\text { NS } \\
\text { NS }\end{array}$ \\
\hline $\begin{array}{l}\text { Fish for dinner } \\
4-7 \text { times per week } \\
1-3 \text { times per week }\end{array}$ & $\begin{array}{c}8.1 \\
43.8\end{array}$ & $\begin{array}{c}7.1 \\
42.6\end{array}$ & $\begin{array}{c}9.5 \\
50.4\end{array}$ & $\begin{array}{c}7.3 \\
46.9\end{array}$ & $\begin{array}{l}\text { NS } \\
\text { NS }\end{array}$ \\
\hline $\begin{array}{l}\text { Pizza } \\
\text { Daily > } \\
4-6 \text { times per week } \\
1-3 \text { times per week }\end{array}$ & $\begin{array}{c}1.4 \\
4.2 \\
38.6\end{array}$ & $\begin{array}{c}4.1 \\
5.9 \\
40.7\end{array}$ & $\begin{array}{c}3.3 \\
3.2 \\
37.9\end{array}$ & $\begin{array}{c}3.2 \\
7.7 \\
49.6\end{array}$ & $\begin{array}{l}\text { NS } \\
\text { NS } \\
* * *\end{array}$ \\
\hline $\begin{array}{l}\text { Hamburgers/hot } \\
\text { dogs/kebabs } \\
\text { Daily > } \\
\text { 4-6 times per week } \\
\text { 1-3 times per week }\end{array}$ & $\begin{array}{c}1.4 \\
2.1 \\
10.9\end{array}$ & $\begin{array}{c}2.5 \\
4.1 \\
22.1\end{array}$ & $\begin{array}{c}1.2 \\
0.9 \\
12.3\end{array}$ & $\begin{array}{c}1.7 \\
6.1 \\
29.1\end{array}$ & $\begin{array}{l}\text { NS } \\
\text { NS } \\
* * *\end{array}$ \\
\hline $\begin{array}{l}\text { Crisps } \\
\text { Daily > } \\
4-6 \text { times per week } \\
1-3 \text { times per week }\end{array}$ & $\begin{array}{c}4.2 \\
6.3 \\
44.9 \\
\end{array}$ & $\begin{array}{c}4.3 \\
7.2 \\
44.5 \\
\end{array}$ & $\begin{array}{c}3.6 \\
8.6 \\
41.4 \\
\end{array}$ & $\begin{array}{c}8.1 \\
13.4 \\
41.3 \\
\end{array}$ & $\begin{array}{l}\text { NS } \\
\text { NS } \\
\text { NS }\end{array}$ \\
\hline $\begin{array}{l}\text { Chips } \\
\text { Daily > } \\
\text { 4-6 times per week } \\
1-3 \text { times per week }\end{array}$ & $\begin{array}{c}0.3 \\
1.1 \\
16.1\end{array}$ & $\begin{array}{c}2.1 \\
3.4 \\
17.7\end{array}$ & $\begin{array}{c}0.0 \\
1.8 \\
15.0\end{array}$ & $\begin{array}{c}0.8 \\
3.2 \\
27.5\end{array}$ & $\begin{array}{l}\text { NS } \\
\text { NS } \\
*\end{array}$ \\
\hline $\begin{array}{l}\text { Chocolate } \\
\text { Daily> } \\
\text { 4-6 times per week } \\
1-3 \text { times per week }\end{array}$ & $\begin{array}{c}8.1 \\
14.0\end{array}$ & $\begin{array}{l}7.5 \\
6.9\end{array}$ & $\begin{array}{l}13.6 \\
18.6\end{array}$ & $\begin{array}{l}17.8 \\
23.1\end{array}$ & $\begin{array}{l}* * * \\
* * *\end{array}$ \\
\hline $\begin{array}{l}\text { Cod-liver oil } \\
\text { Daily > } \\
\text { 4-6 times per week } \\
\text { 1-3 times per week }\end{array}$ & $\begin{array}{l}14.4 \\
3.9 \\
7.7 \\
\end{array}$ & $\begin{array}{c}10.9 \\
6.4 \\
5.3 \\
\end{array}$ & $\begin{array}{l}12.3 \\
4.1 \\
3.2 \\
\end{array}$ & $\begin{array}{l}11.7 \\
3.6 \\
5.7\end{array}$ & $\begin{array}{l}\text { NS } \\
\text { NS } \\
\text { NS }\end{array}$ \\
\hline $\begin{array}{l}\text { Snacks } \\
\text { Daily > } \\
\text { 4-6 times per week } \\
\text { 1-3 times per week }\end{array}$ & $\begin{array}{l}14.0 \\
17.2 \\
51.6\end{array}$ & $\begin{array}{l}13.1 \\
14.0 \\
48.0\end{array}$ & $\begin{array}{l}18.2 \\
20.5 \\
46.8\end{array}$ & $\begin{array}{l}23.5 \\
24.6 \\
37.7\end{array}$ & $\begin{array}{l}* * \\
* * \\
\text { NS }\end{array}$ \\
\hline
\end{tabular}

Asterisks denote the level of statistical significance revealed by logistic regression: $* \mathrm{P}<0.05$; $* * \mathrm{P}<0.01 ; * * * \mathrm{P}<0.001$. NS indicates that change in consumption is not significant. 
Table 3. Trends in daily beverage consumption from the eighth to tenth grade, by gender.

\begin{tabular}{||l|c|c|c|c|c||}
\hline & $\begin{array}{c}\text { EIGHTH-GRADE } \\
\text { (number) }\end{array}$ & $\begin{array}{c}\text { TENTH- } \\
\text { GRADE } \\
\text { BOYS } \\
\% \text { (number) }\end{array}$ & $\begin{array}{c}\text { EIGHTH-GRADE } \\
\text { GIRLS } \\
\text { (number) }\end{array}$ & $\begin{array}{c}\text { TENTH- } \\
\text { GRADE } \\
\text { GIRLS } \\
\%(\text { number) }\end{array}$ & Difference p \\
\hline Water & $91.5 \%(294)$ & $86.6 \%(258)$ & $92.6 \%(264)$ & $90.5 \%(200)$ & NS \\
\hline Juice & $55.4 \%(178)$ & $61.5 \%(182)$ & $49.8 \%(142)$ & $50.9 \%(112)$ & $*$ \\
\hline Squash & $59.2 \%(190)$ & $48.9 \%(185)$ & $47.3 \%(135)$ & $45.0 \%(99)$ & NS \\
\hline $\begin{array}{l}\text { Fizzy } \\
\text { drinks }\end{array}$ & $52.3 \%(168)$ & $74.0 \%(220)$ & $42.1 \%(120)$ & $46.8 \%(103)$ & $* * *$ \\
\hline Milk & $73.6 \%(235)$ & $72.4 \%(215)$ & $63.5 \%(175)$ & $64.0 \%(141)$ & NS \\
\hline
\end{tabular}

Asterisks denote the level of statistical significance revealed by logistic regression: $* \mathrm{P}<0.05$; $* * \mathrm{P}<0.01 ; * * * \mathrm{P}<0.001$. NS indicates that change in consumption is not significant. 